\title{
PCDD/Fs and Dioxin-Like PCBs in Sediments from Yellow Estuary and Yangtze Estuary, China
}

\author{
Yamei Hui $\cdot$ Minghui Zheng $\cdot$ Zhengtao Liu • \\ Lirong Gao
}

Received: 9 March 2009/Accepted: 8 July 2009/Published online: 24 July 2009

(C) Springer Science+Business Media, LLC 2009

\begin{abstract}
Twenty one surface sediments were analyzed for PCDD/Fs and dioxin-like PCBs by HRGC-HRMS in Yellow Estuary and Yangtze Estuary in China. The concentration ranges of 2,3,7,8-substituted PCDD/Fs, dioxinlike PCBs and WHO-TEQ were 2.33-253, 0.04-139 and $0.11-1.01 \mathrm{pg} / \mathrm{g} \mathrm{dw}$ respectively in sediment from two estuaries. For PCDD/Fs and dioxin-like PCBs, OCDD, CB77, CB105 and CB118 were found to be dominant. The pollution levels in two estuaries were lower compared with that in other locations reported by previous studies.
\end{abstract}

Keywords Yellow Estuary - Yangtze Estuary ·

PCDD/Fs $\cdot$ PCBs $\cdot$ Sediment

Polychlorinated dibenzo- $p$-dioxins and dibenzofurans (PCDD/Fs) and dioxin-like PCBs (dl-PCBs) are known to bioaccumulate because of their persistence and lipophilicity. In aquatic environments, these contaminants are removed from the water column and adsorbed onto particulate matter, and finally accumulate in sediments which may play a role as secondary contamination sources. They also accumulate in sediment-dwelling organisms, and may be transferred to higher trophic levels through the food

Y. Hui $\cdot$ M. Zheng $(\bowtie) \cdot$ L. Gao

State Key Laboratory of Environmental Chemistry and Ecotoxicology, Research Center for Eco-Environmental Sciences, Chinese Academy of Sciences, Beijing 100085, China e-mail: zhengmh@ @rcees.ac.cn

Z. Liu

China Research Academy of Environmental Sciences, Beijing

100012, China chain (Mackay et al. 1992). Estuaries can serve as important sources of these organic contaminants to coastal marine environments and also act as sinks for fine-grain sediment and associated particle-reactive contaminants (Feng et al. 1998).

As two of the largest rivers in China, the Yellow River and Yangtze River drain about $1.8 \times 10^{6}$ and $0.75 \times 10^{6}$ $\mathrm{km}^{2}$ area (People's Republic of China Year book 2004), respectively, total covering about $25 \%$ of the territory of the country. Contaminants from the Yellow River Basin (northern China) and Yangtze River Basin (southern China) are ultimately transported by solid and water to estuaries. Yellow Estuary and Yangtze Estuary are major commercial arteries and industrial centers because of Shengli Oilfield (the second largest oil producing base in China) and Shanghai (the biggest metropolitan in China). Therefore, estuarine sediments from these two rivers can serve as field archives not only for ambient environmental conditions but also for the pollution status of dioxins in the upper and middle reach areas. The Yellow River and Yangtze River discharge $1.1 \times 10^{9} \mathrm{t}$ and $0.48 \times 10^{9} \mathrm{t}$ of fine-grained sediments annually to the oceans respectively, accounting for $10 \%$ of the world's annual sediment discharge (Milliman and Syvitski 1992). This huge amount of sediment is one of the major factors affecting the balance of sedimentary and ecological environments in the Bohai Sea, Yellow Sea and East China Sea (Zhang 1999). Although there were a few investigations on levels of PCDD/Fs or PCBs in surface sediments from Yangtze Estuary (Liu et al. 2003; Wen et al. 2008), there were little information about PCDD/Fs and PCBs in surface sediments in Yellow Estuary. The present study aimed to investigate the levels of PCDD/Fs and dl-PCBs and discuss the spatial distributions and potential sources in these two estuaries. 


\section{Materials and Methods}

In Yangtze Estuary, 6 sampling sites were selected adjacent to the city of Shanghai. And 15 sites were in Yellow Estuary, all distributed in Dongying City (Fig. 1). Surface sediment samples were collected using a stainless steel grab sampler in April 2004 in Yangtze Estuary, and August 2004 in Yellow Estuary. All sediment samples were stored frozen at $-20^{\circ} \mathrm{C}$ until laboratory analysis.

Before extraction, samples $(10 \mathrm{~g})$ were spiked with ${ }^{13} \mathrm{C}$-labeled surrogate standards according to the US EPA Method 1613B and 1668A. Extraction was carried out by Soxhlet extraction using $250 \mathrm{~mL}$ toluene for $24 \mathrm{~h}$. The extract was concentrated to about $2 \mathrm{~mL}$ by rotary evaporator and subjected to sulfuric acid wash. The eluate was reduced by rotary evaporation, and a multi-steps cleanup was performed with adsorption chromatography. PCBs fraction was eluted from $10 \mathrm{~g}$ actived alkaline alumina by $100 \mathrm{~mL}$ 5\% dichloromethane in hexane and then PCDD/Fs fraction was eluted by $50 \mathrm{~mL} 50 \%$ dichloromethane in hexane. Afterwards, the extracts were concentrated with gentle nitrogen flow and the solvent was changed to $10 \mu \mathrm{L}$ nonane in a minivial. Before instrumental analysis, ${ }^{13} \mathrm{C}$-labeled injection standards were added and the vial was vortexed to mix completely. The quantification of PCDD/F and PCB homologues was performed by HRGC/ HRMS on an Agilent 6890 gas chromatography coupled with an Autospec Ultima mass spectrometer (Waters, Manchester, UK) operating in the EI mode at $35 \mathrm{eV}$. The GC was equipped with a DB-5MS fused silica capillary column $(60 \mathrm{~m} \times 250 \mu \mathrm{m}$ i.d. $\times 0.25 \mu \mathrm{m}$ film thickness $)$ with helium as carrier gas.

The limit of detection (LOD) for analytes in a given sample was defined by a signal to noise ratio greater than three times the average baseline variation, which ranged from 0.02 to $0.06 \mathrm{pg} / \mathrm{g} \mathrm{dw}$ for PCDD/Fs and 0.03 to $0.07 \mathrm{pg} / \mathrm{g} \mathrm{dw}$ for dl-PCBs. The recovery of labeled compounds of $\mathrm{PCDD} / \mathrm{F}$ and dl-PCB were $75 \pm 14 \%$ and $97 \pm 17 \%$, respectively, which met the limits of US EPA methods. A method blank with each sample batch (12 samples) was checked.

\section{Results and Discussion}

Table 1 provides PCDD/Fs and PCBs results of the sediment samples from Yellow Estuary, while Table 2 provides PCBs results of the sediment samples from Yangtze
Fig. 1 Map of sampling sites. H1-H15: sediments in Yellow Estuary; $C 1-C 6$ : sediments in Yangtze Estuary

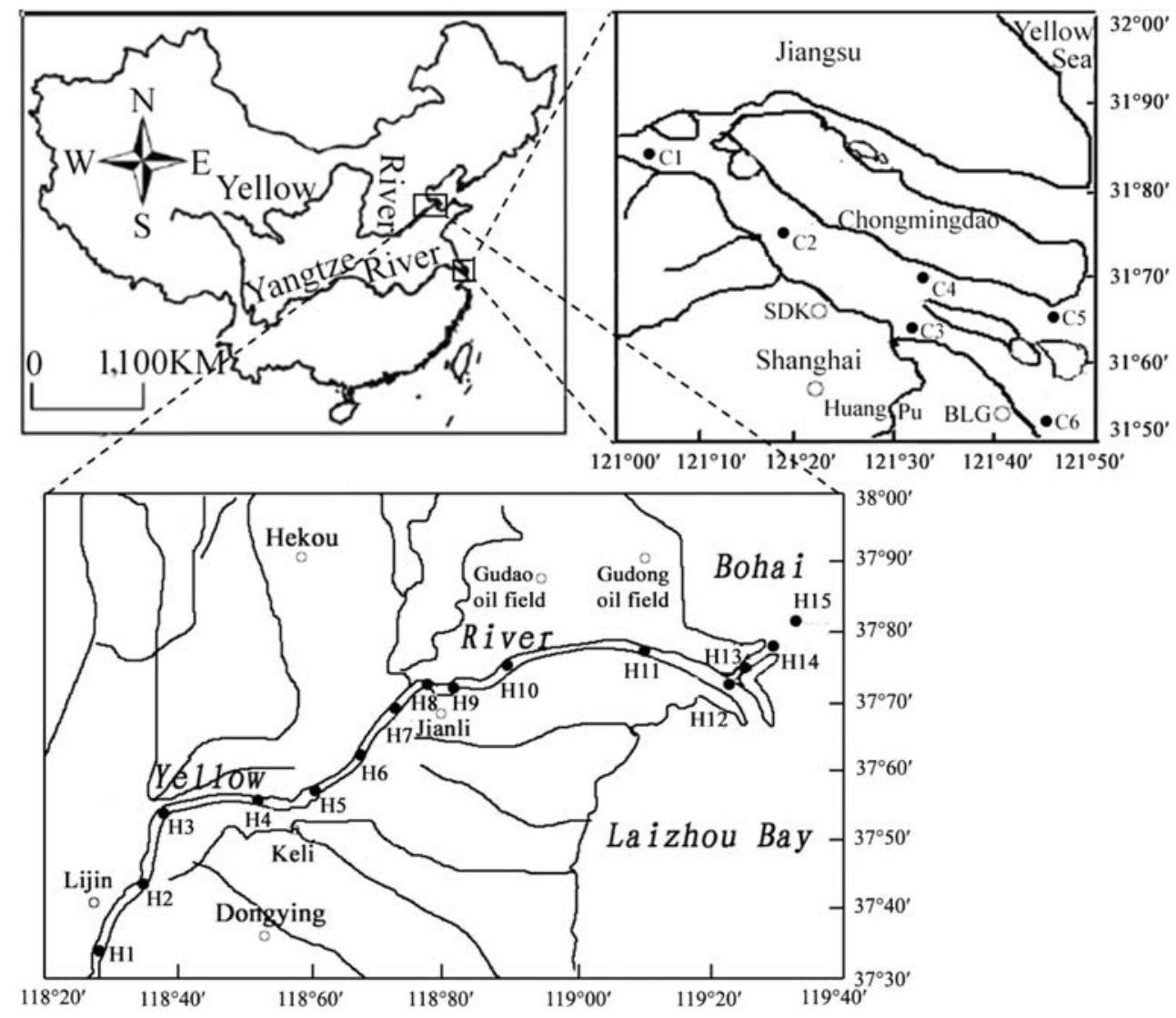


Table 1 Concentrations of PCDD/Fs and dl-PCBs in surface sediments from Yellow Estuary (pg/g dw)

\begin{tabular}{|c|c|c|c|c|c|c|c|c|c|c|c|c|c|c|c|}
\hline & $\mathrm{H} 1$ & $\mathrm{H} 2$ & $\mathrm{H} 3$ & $\mathrm{H} 4$ & H5 & H6 & $\mathrm{H} 7$ & $\mathrm{H} 8$ & H9 & $\mathrm{H} 10$ & $\mathrm{H} 11$ & $\mathrm{H} 12$ & H13 & $\mathrm{H} 14$ & H15 \\
\hline 2378-TCDD & $<0.05$ & $<0.05$ & $<0.09$ & $<0.09$ & $<0.03$ & 0.11 & $<0.09$ & $<0.03$ & $<0.09$ & $<0.05$ & $<0.03$ & $<0.05$ & $<0.05$ & $<0.05$ & $<0.05$ \\
\hline 12378-PeCDD & $<0.07$ & 0.11 & 0.11 & $<0.07$ & $<0.02$ & 0.11 & $<0.07$ & 0.03 & $<0.05$ & 0.11 & 0.28 & $<0.07$ & $<0.06$ & 0.08 & $<0.07$ \\
\hline 123478-HxCDD & $<0.06$ & 0.72 & $<0.06$ & $<0.06$ & $<0.02$ & 0.12 & $<0.04$ & $<0.02$ & $<0.04$ & 0.04 & 0.17 & $<0.04$ & $<0.04$ & $<0.04$ & 0.06 \\
\hline 123678-HxCDD & $<0.04$ & $<0.09$ & $<0.04$ & $<0.04$ & 0.03 & 0.24 & $<0.04$ & $<0.02$ & 0.37 & $<0.03$ & 0.23 & 0.08 & $<0.04$ & 0.07 & 0.15 \\
\hline 123789-HxCDD & $<0.03$ & 0.20 & 0.06 & $<0.03$ & $<0.02$ & $<0.03$ & 0.02 & 0.01 & 0.18 & 0.04 & 0.28 & 0.06 & 0.05 & 0.06 & $<0.03$ \\
\hline 1234678-HpCDD & 2.82 & 3.33 & 2.20 & 0.40 & 0.28 & 3.18 & 0.36 & 0.10 & 0.75 & 0.51 & 5.80 & 1.00 & 2.18 & 0.90 & 1.28 \\
\hline OCDD & 248 & 86.9 & 101 & 64.3 & 3.00 & 79.0 & 12.2 & 1.58 & 1.54 & 12.9 & 187 & 6.00 & 52.0 & 6.70 & 3.90 \\
\hline 2378-TCDF & 0.46 & 0.06 & 0.03 & 0.16 & 0.13 & 0.11 & $<0.08$ & 0.07 & 0.05 & 0.09 & 0.32 & 0.15 & 0.14 & 0.08 & 0.16 \\
\hline 12378-PeCDF & $<0.08$ & $<0.05$ & $<0.08$ & $<0.08$ & $<0.05$ & $<0.08$ & $<0.06$ & $<0.03$ & $<0.05$ & $<0.04$ & $<0.06$ & $<0.06$ & $<0.06$ & $<0.06$ & 0.15 \\
\hline 23478-PeCDF & $<0.06$ & $<0.05$ & $<0.06$ & $<0.06$ & $<0.03$ & $<0.06$ & $<0.04$ & $<0.03$ & $<0.06$ & $<0.04$ & 0.25 & $<0.05$ & $<0.05$ & $<0.05$ & 0.14 \\
\hline 123478-HxCDF & $<0.02$ & $<0.03$ & $<0.04$ & $<0.04$ & 0.03 & 0.20 & $<0.05$ & $<0.04$ & 0.15 & $<0.04$ & 1.20 & $<0.03$ & $<0.04$ & $<0.03$ & 0.16 \\
\hline 123678-HxCDF & $<0.02$ & 0.16 & $<0.03$ & $<0.03$ & 0.02 & $<0.03$ & 0.04 & $<0.08$ & 0.10 & 0.11 & 0.63 & $<0.03$ & 0.03 & 0.03 & 0.10 \\
\hline 234678-HxCDF & $<0.04$ & 0.12 & 0.05 & 0.03 & 0.01 & $<0.04$ & 0.03 & 0.06 & $<0.03$ & 0.10 & 0.42 & 0.06 & 0.05 & 0.09 & $<0.03$ \\
\hline 123789-HxCDF & $<0.03$ & 0.27 & $<0.03$ & $<0.03$ & $<0.02$ & $<0.06$ & 0.03 & $<0.01$ & $<0.03$ & 0.07 & 0.46 & 0.03 & 0.03 & $<0.03$ & 0.05 \\
\hline 1234678-HpCDF & 0.09 & 0.61 & 0.40 & $<0.06$ & 0.05 & 0.69 & 0.31 & 0.26 & 0.14 & 0.19 & 4.4 & $<0.02$ & .24 & .33 & 0.29 \\
\hline 1234789-HpCDF & 0.13 & $<0.02$ & 0.82 & 0.11 & $<0.02$ & $<0.05$ & $<0.02$ & 0.04 & 0.25 & 0.02 & $<0.03$ & 0.25 & 0.55 & 0.29 & 0.41 \\
\hline OCDF & 1.69 & 0.90 & 0.43 & 0.14 & 0.06 & 0.22 & 0.21 & 0.18 & 0.17 & 0.14 & 5.44 & 0.16 & 0.32 & 0.34 & 0.26 \\
\hline CB-77 & 89.2 & 0.65 & 2.20 & 51.4 & 2.30 & $<0.34$ & 1.10 & 0.75 & 0.34 & $<0.34$ & 47.9 & 4.40 & 24.4 & 2.40 & 0.49 \\
\hline CB-81 & 0.35 & $<0.04$ & 0.24 & 0.20 & 0.13 & 0.07 & $<0.02$ & $<0.04$ & $<0.03$ & 0.005 & 0.41 & $<0.06$ & $<0.10$ & 0.07 & $<0.03$ \\
\hline CB-126 & 1.60 & 0.05 & 0.08 & 0.61 & $<0.04$ & $<0.01$ & 0.02 & 0.03 & $<0.02$ & $<0.001$ & 0.68 & 0.09 & 0.35 & 0.07 & $<0.02$ \\
\hline CB-169 & 0.27 & 0.09 & 0.13 & $<0.05$ & 0.03 & 0.12 & $<0.02$ & 0.04 & $<0.03$ & $<0.02$ & 0.12 & $<0.03$ & 0.05 & 0.07 & 0.04 \\
\hline CB-105 & 10.6 & 0.81 & 3.90 & 4.20 & 1.10 & 0.58 & 0.57 & 0.66 & 0.54 & $<0.19$ & 10.7 & 1.60 & 2.00 & 1.40 & 0.52 \\
\hline CB-114 & 1.10 & $<0.02$ & 0.39 & $<0.05$ & 0.12 & 0.06 & $<0.01$ & 0.07 & $<0.02$ & 0.008 & 1.10 & 0.18 & 0.23 & $<0.02$ & $<0.02$ \\
\hline CB-118 & 26.4 & 1.40 & 11.6 & 10.9 & 2.70 & 1.20 & 1.40 & 1.80 & 1.50 & $<0.39$ & 28.8 & 4.30 & 5.40 & 4.20 & 1.60 \\
\hline CB-123 & 3.70 & 0.23 & 1.00 & 1.50 & 0.24 & 0.12 & 0.18 & 0.20 & 0.16 & 0.02 & 3.50 & 0.47 & 0.45 & 0.49 & 0.16 \\
\hline CB-156 & 3.30 & 0.12 & 1.30 & 1.40 & $<0.02$ & 0.11 & 0.15 & 0.22 & 0.13 & $<0.03$ & 3.20 & 0.48 & 0.59 & 0.85 & 0.16 \\
\hline CB-157 & 0.94 & 0.05 & 0.29 & 0.27 & 0.05 & $<0.02$ & 0.04 & $<0.02$ & 0.04 & 0.005 & 0.73 & $<0.03$ & 0.13 & 0.18 & 0.05 \\
\hline CB-167 & 1.50 & 0.05 & 0.46 & 0.58 & $<0.02$ & 0.04 & 0.06 & $<0.02$ & 0.05 & $<0.02$ & 1.20 & 0.20 & 0.27 & 0.28 & $<0.02$ \\
\hline CB-189 & 0.36 & 0.02 & $<0.17$ & 0.13 & $<0.02$ & $<0.02$ & $<0.02$ & $<0.02$ & $<0.02$ & $<0.002$ & $<0.15$ & 0.04 & 0.08 & 0.07 & $<0.02$ \\
\hline Total WHO-TEQ & 0.46 & 0.41 & 0.32 & 0.32 & 0.11 & 0.38 & 0.22 & 0.11 & 0.28 & 0.24 & 1.01 & 0.22 & 0.26 & 0.23 & 0.29 \\
\hline
\end{tabular}

Estuary. The levels of PCDD/Fs in sediment from Yangtze Estuary can be found in our previous report (Sun et al. 2005). Concentrations of total WHO-TEQs (PCDD/ Fs + dl-PCBs) ranged from 0.11 to $1.01 \mathrm{pg} / \mathrm{g} \mathrm{dw}$ in Yellow Estuary and from 0.36 to $0.75 \mathrm{pg} / \mathrm{g} \mathrm{dw}$ in Yangtze Estuary.

In order to determine contamination spatial distributions, 15 samples were grouped into three segments averagely along the lower stretch of estuary: Lower Reach (LR), Delta and River Mouth (RM). Every segment has five sites. Segments were selected based on hydrographical information, river characteristics, discharge of water and silt content, especially socio-economy. There was a similarity distribution profiles between two kinds of pollutants in Yellow Estuary (Fig. 2). Major contributor to contamination was in LR and RM segments where relative higher concentration was observed. The levels varied among different localities probably with positively correlation with anthropogenic activities around the sample sites. There are big oil industrial bases (Dongying District and Hekou District) in south of LR and north of RM but a rural setting and large-scale farms along Delta, so there were the greater potential for dioxins loading on LR and RM segments from atmospheric deposition, urban runoff and municipal and industrial wastewater effluents. Moreover, the mean concentrations of 2,3,7,8-substituted PCDD/Fs and dl-PCBs in LR were obviously higher than that in RM and it was likely due to more urbanized and industrialized in LR and higher content silt in RM. Similarly, there was also a similarity distribution profiles between two kinds of compounds in Yangtze Estuary (Fig. 2). Levels of 2,3,7,8-substituted PCDD/Fs and dl-PCBs are both slightly higher in $\mathrm{C} 1, \mathrm{C} 3$ 
Table 2 Concentrations of dl-PCBs in surface sediments from Yangtze Estuary (pg/g dw)

\begin{tabular}{|c|c|c|c|c|c|c|}
\hline & $\mathrm{C} 1$ & $\mathrm{C} 2$ & $\mathrm{C} 3$ & $\mathrm{C} 4$ & $\mathrm{C} 5$ & C6 \\
\hline CB-77 & 3.10 & 0.33 & 3.80 & 0.42 & 4.30 & 9.10 \\
\hline CB-81 & 0.21 & 0.16 & 0.27 & 0.08 & 0.15 & 0.24 \\
\hline CB-126 & 0.16 & 0.004 & 0.19 & 0.005 & 0.09 & 0.26 \\
\hline CB-169 & 0.07 & 0.05 & 0.08 & 0.03 & 0.06 & 0.09 \\
\hline CB-105 & 5.60 & 1.40 & 3.20 & 0.71 & 1.40 & 6.90 \\
\hline CB-114 & 0.50 & 0.17 & 0.39 & 0.08 & 0.17 & 0.69 \\
\hline CB-118 & 12.5 & 4.10 & 7.60 & 2.00 & 4.10 & 16.6 \\
\hline CB-123 & 1.84 & 0.65 & 1.50 & 0.30 & 0.69 & 2.70 \\
\hline CB-156 & 1.30 & 0.18 & 1.00 & 0.10 & 0.43 & 2.10 \\
\hline CB-157 & 0.32 & 0.07 & 0.27 & 0.04 & 0.12 & 0.55 \\
\hline CB-167 & 0.47 & 0.07 & 0.40 & 0.06 & 0.14 & 0.71 \\
\hline CB-189 & 0.20 & 0.003 & 0.25 & $<0.04$ & 0.04 & 0.30 \\
\hline $\left.\mathrm{WHO}_{\mathrm{TEQ}} \mathrm{PCDD} / \mathrm{Fs}\right)^{\mathrm{a}}$ & 0.56 & 0.36 & 0.42 & 0.60 & 0.74 & 0.57 \\
\hline $\mathrm{WHO}^{-T E Q_{(\mathrm{dl}-\mathrm{PCBs})}}$ & 0.02 & 0.002 & 0.02 & 0.001 & 0.01 & 0.03 \\
\hline Total WHO-TEQ & 0.58 & 0.36 & 0.44 & 0.60 & 0.75 & 0.60 \\
\hline
\end{tabular}

$\left.{ }^{\mathrm{a}} \mathrm{WHO}_{\mathrm{TEQ}} \mathrm{PCDD} / \mathrm{Fs}\right)$ is calculated based on the data from Sun et al. (2005)

and C6. The peak in $\mathrm{C} 1$ may be the result of high pollution from upstream. Site C3 is at the lower stream of Shidongkou (SDK) sewage outlets and at the influx of Huang $\mathrm{Pu}$ tributary into the mainstream of Yangtze River. Site C6 is proximity to Bailonggang (BLG) sewage outlets. So the pollutants may be from sewage discharge of sewage outlets and the water effluent of the Yangtze River.

Although the level of 2,3,7,8-substituted PCDD/Fs is far higher than that of dl-PCBs, the horizontal distribution of 2,3,7,8-substituted PCDD/Fs is consistent with that of dlPCBs in two estuaries (Fig. 2). A sudden increase in the concentrations of total 2,3,7,8-substituted $\mathrm{PCDD} / \mathrm{Fs}$ in sediments at a given station of two estuaries is accompanied by increases in that of total dl-PCBs, with the exception of two samples (H6 and C6). Consequently, strong correlations between concentrations of PCDD/Fs and dl-PCBs were found in this study. These results could be indicative that the source of the two classes of compounds at each site is analogous.

In the two estuaries, the concentration of PCDDs is over 10 times higher than that of PCDFs in most sites. This hints that incineration is not a major contributor in two estuaries. The congener profiles of $\mathrm{PCDD} / \mathrm{Fs}$ at various sites are similar, and the inventory profiles are dominated by OCDD (42-99\%), HpCDD(1-20\%), and OCDF (<8\%) (Fig. 3). This corresponds well with the impurities in some organochlorine pesticides (such as PCP and so on) used in China. Moreover, the contamination of PCDD/Fs in two estuaries might also stem from atmospheric dry and wet precipitation. For dl-PCBs, lower chlorinated congeners (CB77, CB118, and CB105) were found to be dominant, while highly chlorinated congeners was substantially lower (Fig. 3). Thus, PCBs in two estuaries are possibly derived from use or production of Chinese technical product of PCB3.

In two estuaries, greater than $60 \%$ of the total TEQ concentrations in most sediment samples were contributed by PCDDs. The contributions to TEQs decreased in the order of PCDDs $>$ PCDFs $>$ non-ortho PCBs $>>$ monoortho PCBs (Fig. 4). This suggests that PCDD/Fs were the major contributor to total TEQ for surface sediments from two estuaries. Total concentrations of TEQ in all sediment samples in two estuaries didn't exceed the sediment quality guideline (SQG) of $1.4 \times 10^{-2}$ to $2.1 \times 10^{2} \mathrm{pg} / \mathrm{g} \mathrm{dw}$, reported for dioxin equivalents (Iannuzzi et al. 1995). Compared with several other locations in the world, TEQs of PCDD/Fs and PCBs in sediments from two estuaries were close to those in the sediments of clean areas (Table 3). Although the levels of dioxins in two estuaries are low in comparison with many other aquatic systems, it is a challenge that dioxins pollution keep at lower levels with the rapid economy development along Yellow River and Yangtze River.

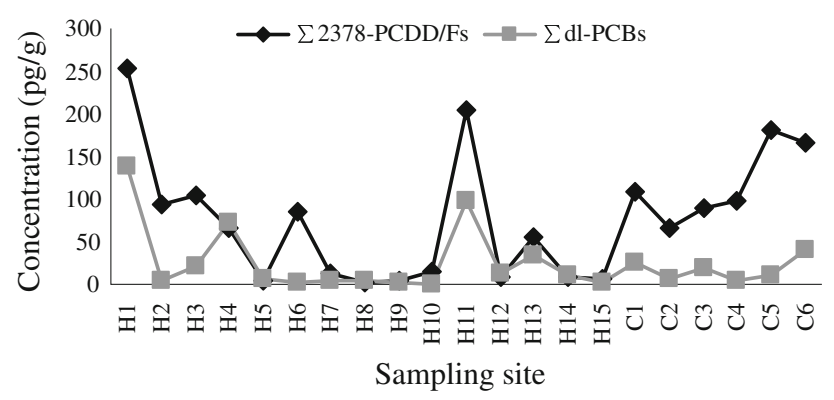

Fig. 2 Horizontal profiles of PCDD/Fs and dl-PCBs concentrations in surface sediments from Yellow Estuary $(\mathrm{H} 1-\mathrm{H} 15)$ and Yangtze Estuary (C1-C6)

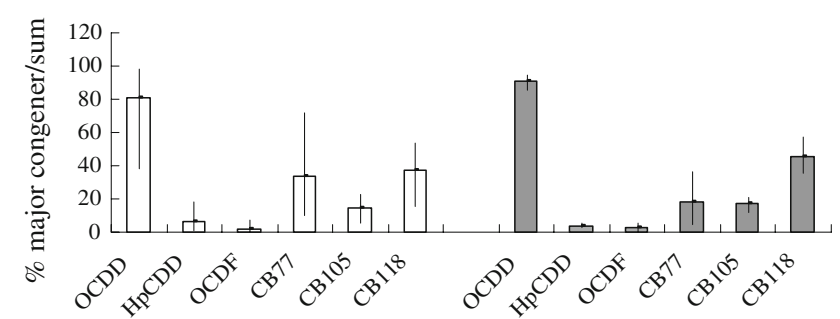

Fig. 3 Calculated ratios between the major congeners of a given class of a given class of contaminant and the sum of all the congeners of that given class, in Yellow Estuary (white) and Yangtze Estuary (dark grey) 


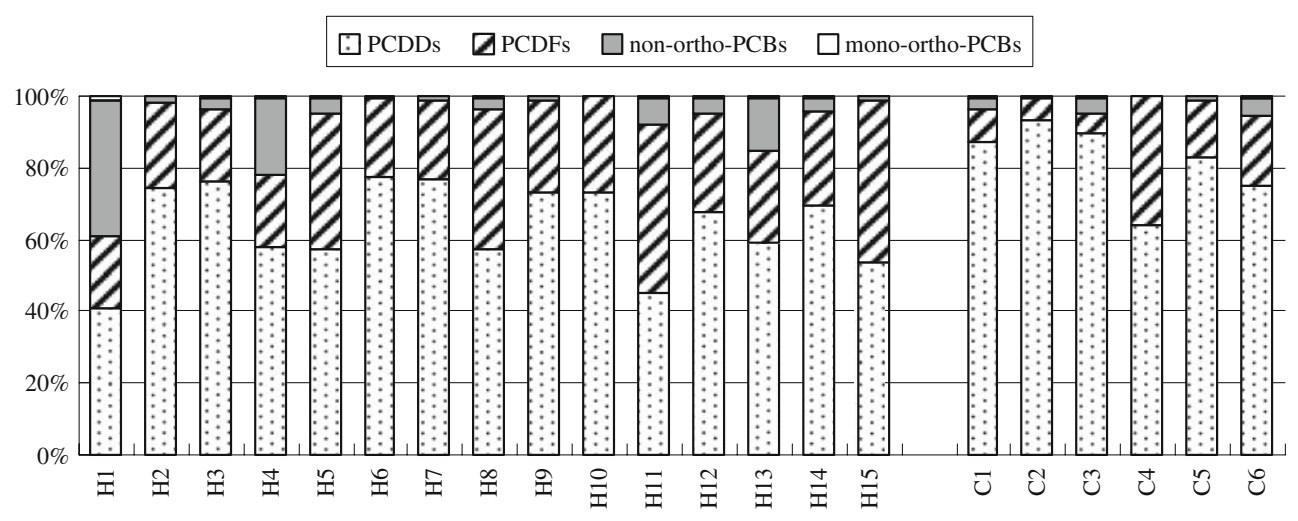

Fig. 4 Contribution to toxicity (\% TEQ) of the different classes of contaminants (PCDDs, PCDFs, non-ortho-PCBs, mono-ortho-PCBs) in Yellow Estuary $(\mathrm{H} 1-\mathrm{H} 15)$ and Yangtze Estuary $(\mathrm{Cl}-\mathrm{C} 6)$

Table 3 Comparison of dioxins TEQ levels (pg/g dry wt.) in surface sediments of different regions

\begin{tabular}{lccc}
\hline Location & PCDD/Fs & PCBs & References \\
\hline Coast, Spain & $0.1-48$ & $0.2-63$ & Eljarrat et al. (2005) \\
Dagu Drainage River, China & $21-89$ & $1.2-21$ & Liu et al. (2007) \\
Haihe River, China & $1.4-19$ & $0.07-0.53$ & Koh et al. (2004) \\
Hyeongsan River, Korea & $0.38-1,037$ & $0.05-3.37$ & Castro-Jiménez et al. (2008) \\
Lake Maggiore, Italy & $0.1-17$ & $0.03-6$ & El-Kady et al. (2007) \\
Nile River, Egypt & $1.8-38.1$ & $0.08-1.3$ & Eljarrat et al. (2001) \\
Northwest Mediterranean & $0.4-39.24$ & $0.03-24.75$ & Fattore et al. (2002) \\
Po River, Italy & $1.3-13$ & & Zhang and Jiang (2005) \\
Taihu Lake, China & $0.83-17.72$ & & Hosomi et al. (2003) \\
Tokyo Bay, Japan & $3.1-49$ & $0.18-3.0$ & Sakai et al. (2008) \\
Toyano lagoon, Japan & $0.49-76$ & & This study \\
Yangtze Estuary, China & $0.36-0.74$ & $0.001-0.03$ & This study \\
Yellow Estuary, China & $0.11-1.01$ & $0.00004-0.18$ &
\end{tabular}

Acknowledgments This research was supported by the Key Project of Chinese Academy of Sciences (No. KZCX2-YW-420), National 973 program (2009CB421606) and National Natural Science Foundation of China (No. 20621703).

\section{References}

Castro-Jiménez J, Mariani G, Eisenreich SJ, Christoph EH, Hanke G, Canuti E, Skejo H, Umlauf G (2008) Atmospheric input of POPs into Lake Maggiore (Northern Italy): PCDD/F and dioxin-like PCB profiles and fluxes in the atmosphere and aquatic system. Chemosphere 73:S122-S130

Eljarrat E, Caixach J, Rivera J, De Torres M, Ginebreda A (2001) Toxic potency assessment of non- and mono-ortho PCBs, PCDDs, PCDFs, and PAHs in northwest mediterranean sediments (Catalonia, Spain). Environ Sci Technol 35:3589-3594

Eljarrat E, De La Cal A, Larrazabal D, Fabrellas B, Fernandez-Alba AR, Borrull F, Marce RM, Barcelo D (2005) Occurrence of polybrominated diphenylethers, polychlorinated dibenzo-p-dioxins, dibenzofurans and biphenyls in coastal sediments from Spain. Environ Pollut 136:493-501

El-Kady AA, Abdel-Wahhab MA, Henkelmann B, Belal MH, Morsi MKS, Galal SM, Schramm KW (2007) Polychlorinated biphenyl, polychlorinated dibenzo-p-dioxin and polychlorinated dibenzofuran residues in sediments and fish of the River Nile in the Cairo region. Chemosphere 68:1660-1668

Fattore E, Vigan L, Mariani G, Guzzi A, Benfenati E, Fanelli R (2002) Polychlorinated dibenzo-p-dioxins and dibenzofurans in River Po sediments. Chemosphere 49:749-754

Feng H, Cochram JK, Lwiza H, Brownawell BJ, Hirschberg DJ (1998) Distribution of heavy metal and PCB contaminants in the sediments of an urban estuary: the Hudson River. Mar Environ Res 45:69-88

Hosomi M, Matsuo T, Dobashi S, Katou S, Abe H (2003) Survey of dioxins in Tokyo Bay bottom sediment. Marine Pollut Bull 47: $68-73$

Iannuzzi TJ, Bonnevie NL, Wenning RJ (1995) An evaluation of current methods for developing sediment quality guidelines for 2,3,7,8-tetrachlorodibenzo-p-dioxin. Arch Environ Contam Toxicol 28:366-377

Koh CH, Khim JS, Kannan K, Villeneuve DL, Senthilkumar K, Giesy JP (2004) Polychlorinated dibenzo-p-dioxins (PCDDs), dibenzofurans (PCDFs), biphenyls (PCBs), and polycyclic aromatic hydrocarbons (PAHs) and 2, 3, 7, 8-TCDD equivalents (TEQs) in sediment from the Hyeongsan River, Korea. Environ Pollut 132: 489-501

Liu M, Yang Y, Hou L, Xu S, Ou D, Zhang B, Liu Q (2003) Chlorinated organic contaminants in surface sediments from the 
Yangtze Estuary and nearby coastal areas, China. Mar Pollut Bull 46:672-676

Liu HX, Zhang QH, Wang YW, Cai ZW, Jiang GB (2007) Occurrence of polychlorinated dibenzo-p-dioxins, dibenzofurans and biphenyls pollution in sediments from the Haihe River and Dagu Drainage River in Tianjin City, China. Chemosphere 68:17721778

Mackay D, Shiu WY, Ma KC (1992) Illustrated handbook of physical-chemical properties and environmental fate for organic chemicals, vol. II. Lewis Publishers, Chelsea

Milliman JD, Syvitski JPM (1992) Geomorphic/tectonic control of sediment discharge to the ocean-the importance of small mountainous rivers. J Geol 100:525-544

Sakai M, Seike N, Kobayashi J, Kajihara H, Takahashi Y (2008) Mass balance and long-term fate of PCDD/Fs in a lagoon sediment and paddy soil, Niigata, Japan. Environ Pollut 156:760-768
Sun YZ, Zhang B, Gao LR, Liu ZT, Zheng MH (2005) Polychlorinated dibenzo-p-dioxins and dibenzofurans in surface Sediments from the estuary area of Yangtze River, People's Republic of China. Bull Environ Contam Toxicol 75:910-914

Wen S, Hui Y, Yang FX, Liu ZT, Xu Y (2008) Polychlorinated dibenzop-dioxins (PCDDs) and dibenzofurans (PCDFs) in surface sediment and bivalve from the Changjiang Estuary, China. Chin J Oceanol Limnol 26:35-44

Zhang J (1999) Heavy metal compositions of suspended sediments in the Changjiang estuary: significance of riverine transport to the ocean. Cont ShelfRes 19:1521-1543

Zhang QH, Jiang GB (2005) Polychlorinated dibenzo-p-dioxins/furans and polychlorinated biphenyls in sediments and aquatic organisms from the Taihu Lake, China. Chemosphere 61:314-322 